\title{
GLI1 is increased in ovarian endometriosis and regulates migration, invasion and proliferation of human endometrial stromal cells in endometriosis
}

\author{
Hengwei Liu ${ }^{1}$, Wei Zhang ${ }^{1}$, Lili Wang ${ }^{2}$, Zhibing Zhang ${ }^{3,4}$, Wenqian Xiong ${ }^{5}$, Ling Zhang ${ }^{5}$, Tian Fu ${ }^{5}$, \\ Xiaoou $\mathrm{Li}^{5}$, Yaobing $\mathrm{Chen}^{6}$, Yi Liu \\ ${ }^{1}$ Department of Obstetrics and Gynecology, Zhongnan Hospital of Wuhan University, Wuhan University, Wuhan 430071, China; ${ }^{2}$ Department \\ of Obstetrics and Gynecology, Wuhan Fourth Hospital, Puai Hospital, Tongji Medical College, Huazhong University of Science and Technology, \\ Wuhan 430032, China; ${ }^{3}$ Department of Physiology, ${ }^{4}$ Department of Obstetrics and Gynecology, Wayne State University, Detroit, Michigan, USA; \\ ${ }^{5}$ Department of Obstetrics and Gynecology, Union Hospital, Tongji Medical College, Huazhong University of Science and Technology, Wuhan \\ 430022, China; 'Institute of Pathology, Tongji Hospital, Tongji Medical College, Huazhong University of Science and Technology, Wuhan 430030, \\ China \\ Contributions: (I) Conception and design: Y Liu, Y Chen; (II) Administrative support: Z Zhang, W Zhang; (III) Provision of study materials or \\ patients: T Fu, X Li; (IV) Collection and assembly of data: H Liu, L Wang; (V) Data analysis and interpretation: All authors; (VI) Manuscript \\ writing: All authors; (VII) Final approval of manuscript: All authors. \\ Correspondence to: Yaobing Chen. Institute of Pathology, Tongji Hospital, Tongji Medical College, Huazhong University of Science and Technology, \\ Wuhan 430030, China. Email: 2013TJ0513@hust.edu.cn; Yi Liu. Department of Obstetrics and Gynecology, Union Hospital, Tongji Medical \\ College, Huazhong University of Science and Technology, Wuhan 430022, China. Email: liqun1994@hust.edu.cn.
}

Background: Endometriosis is a benign gynecological disorder which shares certain characteristics with malignant tumor like migration, invasion and proliferation. Glioma-associated oncogene homolog 1 (GLI1) has been implicated in some cancers including endometrial cancer, however, its role in endometriosis remains unknown.

Methods: The aim of this study was to explore the expression pattern of GLI1 in endometriosis, and further investigate the effect of GLI1 regulation on human endometrial stromal cells. The expression of GLI1 in normal endometrium and ectopic tissues was analyzed by immunohistochemistry, quantitative reverse transcription-polymerase chain reaction (qRT-PCR) and western blot. The Short hairpin RNA (ShRNA) intervention technique and GLI1 inhibitor GANT-61 were used to silence GLI1. The expression levels of GLI1, MMP2 and MMP9 was detected by qRT-PCR and western blot. The migration and invasion ability of human endometrial stromal cells was determined by wound healing assay and transwell migration/ invasion assay. The viability and proliferation potentiality of cells was detected by MTT assays and colony formation assay, respectively.

Results: We found that the expression of GLI1 mRNA and protein were significantly higher in ectopic endometrium from patients with endometriosis. Our analyses also show that GLI1 downregulation attenuated cells migration, invasion and proliferation abilities. What's more, reduced expression of GLI1 inhibited the expression of matrix metalloproteinase 2 (MMP2) and matrix metalloproteinase 9 (MMP9).

Conclusions: Our findings suggest that high levels of GLI1 may contribute to the development of endometriosis by promoting cell migration, invasion and proliferation involving regulation of MMP2 and MMP9 expression. Therefore, inhibition of GLI1 might be a novel potential therapeutic approach to the treatment of endometriosis, which sheds new light on our understanding of the pathogenesis of endometriosis.

Keywords: Glioma-associated oncogene homolog 1 (GLI1); migration; invasion; proliferation; endometriosis 
Submitted Jun 21, 2019. Accepted for publication Sep 22, 2019.

doi: $10.21037 /$ atm.2019.10.76

View this article at: http://dx.doi.org/10.21037/atm.2019.10.76

\section{Introduction}

Endometriosis, a common gynecological benign disorder, is classically characterized by the presence of endometriallike tissue outside of the uterine cavity, primarily the pelvic peritoneum, ovaries, and rectovaginal septum (1). Affecting $10-15 \%$ of female population of reproductive age, the stigmata of endometriosis include dysmenorrhea, dyspareunia, chronic pelvic pain and infertility (2). The formation of a lesion depends on the survival, attachment, growth, neo-angiogenesis, and invasion of the endometrial cells at the ectopic sites $(3,4)$. Despite many years of research, until now, the etiology and pathogenesis of endometriosis remains poorly understood. Moreover, an effective strategy to prevent and control the endometriosis development is still lacking. Therefore, the underlying molecular and cellular mechanisms linking the pathogenesis of endometriosis need to be unraveled that could be further manipulated to explore new effective approaches for endometriosis therapy.

The Hedgehog $(\mathrm{HH})$ signaling pathway is an essential mediator of multiple fundamental biological events including embryogenesis, tissue polarity, adult tissue homeostasis, and carcinogenesis. There are three distinct $\mathrm{HH}$ family members in mammals, including Sonic hedgehog (SHH), Indian hedgehog (IHH) and Desert hedgehog (DHH) (5). The activation of shh signaling is triggered by an extracellular secreted protein, $\mathrm{SHH}$, which binds and inhibits a 12 -pass transmembrane receptor protein Patched (PTCH). When Shh binds to the PTCH receptor, Smoothened (SMO) protein is no longer inhibited and released to activate the translocation of the glioma-associated oncogene homolog 1 (GLI1) from cytoplasmic into the nucleus (6). GLI1 acts as the strongest transcriptional activator downstream of the SHH pathway, whose nuclear translocation serves as a reliable indicator of SHH pathway activation. Previous studies have shown that the abnormal activation of GLI1 resulting in the increased transcription of target genes which regulate multiple biological processes including proliferation, apoptosis, migration and invasion (7-9). Abnormal activation of GLI1 has been found in several types of female reproductive cancer, such as ovarian cancer or breast cancer $(10,11)$. As we all know, endometriosis is a benign disease, but it shares certain characteristics with malignant tumors, such as invasive and unrestrained ectopic cell growth (12). The aberrant expression of GLI1 in endometrial carcinomas has also been described $(13,14)$. Previous research reported that GLI1 is temporary increased in the glandular nuclei and cytoplasm of normal secretory phase endometrium when compared to the proliferative phase (15). Besides, the abnormal activation of sonic hedgehog (SHH) signaling pathway was also observed in endometriosis (16). However, the expression and function of the GLI1 in human ovarian endometriosis remains to be elucidated. Therefore, the goal of this study is to gain further insight of endometriosis pathogenesis by identifying the expression and spatial distribution of GLI1 in ovarian endometriotic tissues and further investigate the role of GLI1 on the biological behavior of endometrial stromal cell.

\section{Methods}

\section{Ethical approval}

The study was approved by Institutional Ethics Committee of Tongji Medical College, Huazhong University of Science (IORG No: IORG0003571) and written consent was provided by every participant before inclusion.

\section{Patients and tissue collection}

Tissue specimens were acquired during 2014 and 2016 at the Department of Obstetrics and Gynecology, Union Hospital, Tongji Medical College, Huazhong University of Science and Technology from non-pregnant women of reproductive age. The recruited patients had regular menstrual cycles (between 26 and 32 days), with confirmation of their menstrual history. None of the women had taken any hormone treatments for at least 6 months before surgery.

Thirty-one cases of normal endometrial tissues were collected from healthy fertile women who were undergoing laparoscopic tubal ligation by hysteroscopy. Thirty specimens of ovarian endometriotic tissues were obtained from patients who underwent laparoscopic surgery or hysterectomy. Among them, twenty-three women suffer from pain or infertility. At the time of tissue collection, 
Table 1 Clinical characteristics of patients

\begin{tabular}{|c|c|c|c|}
\hline Characteristics & \multicolumn{2}{|c|}{ Samples used for immunohistochemistry } & $\begin{array}{l}\text { Stromal cells from eutopic } \\
\text { endometrium of cases with endometriosis }\end{array}$ \\
\hline Number of cases & 31 & 30 & 27 \\
\hline Age & $32.6 \pm 4.9$ & $38.2 \pm 5.8$ & $36.2 \pm 5.3$ \\
\hline Menstrual cycle phase & Proliferative & Proliferative & Proliferative \\
\hline III & - & 19 & - \\
\hline IV & - & 11 & - \\
\hline Pain & - & 25 & - \\
\hline Infertility & - & 17 & - \\
\hline
\end{tabular}

all participants were in the proliferative phase of the menstrual cycle. The stage of the ovarian endometriotic tissues was classified according to the revised American Society for Reproductive Medicine Revised Classification of Endometriosis (ASRM). The endometrial tissues were collected using the Nowak's curette just before the surgical procedure and all specimens were immediately frozen and stored in liquid nitrogen for RNA and protein extraction or paraffin embedded for immunohistochemistry. The clinical characteristics and menstrual phases of each group are summarized in Table 1.

\section{Immunobistochemistry}

Immunohistochemical staining was performed as described in our previous study (17). Briefly, endometrium tissue specimens were fixed in $10 \%$ formalin and paraffin embedded using standard procedures. Consecutive 5 -mm sections were cut from paraffin blocks and placed on poly-L-lysine-coated coverslips. The dried coverslips were deparaffinized, rehydrated, and subjected to antigen retrieval in sodium citrate solution ( $\mathrm{pH}$ 6.0) for 30 minutes in a steamer. The sections were blocked with $3 \%$ hydrogen peroxide for 30 minutes at room temperature (RT). Then followed by 30 minutes' incubation with $1 \%$ bovine serum albumin to block nonspecific binding. After three washes with PBS, rabbit polyclonal antibody directed against GLI1 (diluted 1:200; Abcam, Cambridge, UK) was applied for overnight at $4{ }^{\circ} \mathrm{C}$. In the negative controls, the primary antibodies were incubated with an isotype-matched rabbit IgG antibody. Sections were subsequently washed with
PBS and incubated with peroxidase-labelled anti-rabbit IgG (diluted 1:500; Servicebio Biotech, Wuhan, China) for 30 minutes at RT. 3,30-Diaminobenzidine tetrahydrochloride substrate (DAB) (Beyotime, Wuhan, China) was used as a substrate and sections were lightly counterstained with hematoxylin, dehydrated, and mounted. Characteristics of antibody used for immunohistochemistry are listed in Table S1.

\section{Semi-quantitative analysis of immunobistochemical staining}

The analysis of immunohistochemistry results was independently carried out by two observers. We utilized immunohistochemical scores (IHS) based on the German Immuno-Reactive score (18). Briefly, nuclear GLI1 staining was defined as positive (1) or negative (0), while GLI1 cytoplasmic expression was scored semi-quantitatively. The cytoplasmic score used was the sum of the percentage of GLI1-positive cells ( 0 : no staining; $1: 1-10 \%$ of positive cells; 2 : $11-50 \%$ of positive cells; and 3: $51-80$ of positive cells; and 4: $81-100 \%$ of positive cells) and the staining intensity (0: negative; 1 : weak; 2 : moderate; and 3: strong). Samples with scores $0-2$ were considered negative $(0)$ and scores 3-6 were considered positive (1).

\section{Isolation and culture of primary buman endometrial stromal cells}

The primary human endometrial stromal cells were isolated from eutopic endometrium from patients with 
endometriosis as previously described, with minor modifications (19). Briefly, the collected endometrial tissues were minced into $1 \mathrm{~mm}^{3}$ pieces and digested in PBS containing $2 \mathrm{mg} / \mathrm{mL}$ of type II collagenase $(0.1 \%$, SigmaAldrich) at $37^{\circ} \mathrm{C}$ for $45-60$ minutes with constant agitation. After digestion for 40 minutes, stromal cells were separated from debris and epithelial cells by progressive filtration through 150 and $37.4 \mu \mathrm{m}$ sieves. After this step, filtered stromal cells were dispensed for adherent growth and maintained in Dulbecco's modified Eagle's/F12 medium (DMEM/F12; HyClone) supplemented with $20 \%$ fetal bovine serum (FBS; HyClone), $100 \mathrm{U} / \mathrm{mL}$ penicillin, and $100 \mathrm{mg} / \mathrm{mL}$ streptomycin (HyClone) in humidified atmosphere with $5 \% \mathrm{CO}_{2}$ at $37{ }^{\circ} \mathrm{C}$. The purity of isolated stromal cells was $>95 \%$ and stromal cells were contaminated by less than $1 \%$ of epithelial cells, as determined by diffuse and strong cytoplasmic immunostaining for Vimentin (diluted 1:50; Abcam, Cambridge, UK) and negative cellular staining for E-cadherin (diluted 1:50; Abcam, Cambridge, UK) in immunocytochemistry.

\section{Immunocytochemical staining of human endometrial stromal cells}

The immunocytochemistry was conducted as reported previously (20). Briefly, endometrial stromal cells were plated in a 6-well plate which contains coverslips $\left(2 \times 10^{4}\right.$ cells/well $)$ and grown until approximately $70 \%$ confluency. Then, endometrial stromal cells were washed two times and fixed with $4 \%$ paraformaldehyde at $4{ }^{\circ} \mathrm{C}$ for $15 \mathrm{~min}$. To increase cell permeability to antibodies, endometrial stromal cells were soaked in $0.3 \%$ Triton X-100 (Sigma, Belgium) for $15 \mathrm{~min}$. Non-specific binding site of antigens was avoided by rinsing with $10 \%$ bovine serum albumin (BSA) in PBS for $1 \mathrm{~h}$ at room temperature, followed by incubation with primary antibodies of E-cadherin (diluted 1:50; Abcam, Cambridge, UK) and Vimentin (diluted 1:50; Abcam, Cambridge, UK) overnight at $4{ }^{\circ} \mathrm{C}$, and then with horseradish peroxidase-conjugated secondary antibody (diluted 1:500; Servicebio Biotech, Wuhan, China) for $2 \mathrm{~h}$ at room temperature. Images were collected using a Nikon DXM1200C digital camera. Characteristics of antibody used for immunocytochemical staining are listed in Table S1.

\section{Isolation of total RNA and quantitative real-time polymerase chain reaction ( $q R T-P C R)$ analysis}

Total RNA was isolated using Trizol reagent (TaKaRa,
Dalian, China) from collected endometrium tissues and cultured cells according to manufacturer's product protocol. Then reverse transcription was performed using PrimeScript RT reagent kit (TaKaRa, Dalian, China), and $1 \mu \mathrm{g}$ of total RNA was reverse transcribed in a $20 \mu \mathrm{L}$ volume. The prepared single strand cDNA was used as the template for real-time quantitative PCR. Real-time PCR was performed using the SYBR Premix Ex TaqTM (Takara, Japan) in a Step-One-Plus-TM real-time PCR system (Applied Biosystems Inc, Foster City, CA, USA). The cycling conditions were set at $95^{\circ} \mathrm{C}$ for $5 \mathrm{~min}$, and followed by 40 cycles at $95{ }^{\circ} \mathrm{C}$ for $10 \mathrm{~s}$, at $60^{\circ} \mathrm{C}$ for $5 \mathrm{~s}$ and at $72{ }^{\circ} \mathrm{C}$ for $15 \mathrm{~s}$, with a final melting curve analysis. The qRT-PCR results were recorded and analyzed using the instrument's application software. GAPDH was used as an internal standard for quantification of mRNA expression. The primer sequences are listed in the Table $S 2$.

\section{Protein extraction and western blot analysis}

Collected endometrial tissues and cultured endometrial stromal cells were separately homogenised with radio immunoprecipitation assay (RIPA) lysis buffer (Beyotime Biotechnology, China) and protease inhibitors (Sigma, USA). Total and nuclear proteins were extracted according to the manufacturer's instructions (Beyotime, Haimen, China). After keeping on ice for 30 minutes and centrifuging at $12,000 \mathrm{~g}$ at $4{ }^{\circ} \mathrm{C}$ for 15 minutes, the supernatants were collected. Protein concentration was detected using the BCA protein quantitative analysis kit (Beyotime Biotechnology, China). Then cell lysates were boiled for 5 min at $95{ }^{\circ} \mathrm{C}$ and stored at $-20{ }^{\circ} \mathrm{C}$. Equal amounts of protein samples were loaded on a $10 \%$ sodium dodecyl sulfate-polyacrylamide gel with $1 \times$ running buffer. Run the SDS-PAGE gel as recommended by the manufacturer: 45 minutes at $80 \mathrm{~V}$ then followed by 90 minutes at $120 \mathrm{~V}$. The proteins separated by SDS-PAGE gel was transferred to a polyvinyl difluoride (PVDF) membrane (Millipore, Bedford, MA, USA). The membranes were blocked by $5 \%$ defatted milk in Tris-buffered saline containing $0.05 \%$ Tween 20 for $2 \mathrm{~h}$ at room temperature, and were incubated with the polyclonal rabbit anti-GLI1 antibody (diluted 1:1,000; Abcam, Cambridge, UK), polyclonal rabbit antiMMP2 antibody (diluted 1:750; Affinity, USA), polyclonal rabbit anti-MMP9 antibody (diluted 1:750; Affinity, USA) and the rabbit anti-GAPDH antibody (diluted 1:3,000; Proteintech, USA) overnight at $4{ }^{\circ} \mathrm{C}$. The blots were then washed and incubated at room temperature for $1 \mathrm{~h}$ 
in peroxidase-conjugated goat anti-rabbit IgG secondary antibodies (1:5,000; Santa Cruz Biotechnology, Santa Cruz, CA, USA). The membranes were washed again and then processed for chemiluminescence with ECL-Western blot detecting reagent (Millipore. USA) according to the manufacturer's recommendations. Densitometry of the protein bands were observed by imaging system (Gel Doc 2000; Bio-Rad, USA) and analysis with Image J software (NIH) (version 1.5, USA). Characteristics of antibody used for western blotting are listed in Table S1.

\section{Adenovirus infection}

Adenovirus-mediated short hairpin RNA (shRNA) targeting GLI1 (Cat. no. HB-632179) and non-target control adenoviral particles encoding a scrambled shRNA sequence (Cat. no. HB-000020) were purchased from HanBio Technology Co. Ltd. (Shanghai, China). Cell infection assay was performed according to the manufacturer's recombinant adenovirus operation manual. Briefly, endometrial stromal cells were plated in 6-well plates at a density of $2 \times 10^{4}$ cells/well and grown until they reached approximately $60 \%$ confluence. Then cells were infected by adding 100 MOI (multiplicity of infection) $/ \mathrm{mL}$ prepared virus to each well. After incubated for $6 \mathrm{~h}$, the culture medium was replaced $6 \mathrm{~h}$ later with fresh medium and incubated for another $24 \mathrm{~h}$. The efficiency of cell infection was determined by observing the expression of green fluorescent protein (GFP) under an inverted fluorescence microscope (IX51, Olympus, Tokyo, Japan).

\section{Transwell migration and invasion assays}

The 24-well transwell chambers (Corning Costar, Tewksbury, MA, USA) were used to monitor the migration and invasion ability of human endometrial stromal cells. For the migration assay, $2 \times 10^{5}$ endometrial stromal cells in $200 \mu \mathrm{L}$ of serum-free medium were seeded to each of the upper chamber. The lower chamber was filled with $600 \mu \mathrm{L}$ of DMEM/F12 medium containing 20\% fetal bovine serum as chemo-attractants. After incubation for $48 \mathrm{~h}$, then the cells on upper surface of the filter were removed by wet cotton swab. The cells on the lower surface of the membrane were fixed by methanol for $20 \mathrm{~min}$, then stained with $0.1 \%$ crystal violet for another $20 \mathrm{~min}$ and washed three times with PBS. The cells on the underside of the lower surface were observed and photographed under an Eclipse TE2000-S inverted microscope system with a CCD (Nikon UK) camera at $\times 200$ magnification. For each experiment, the cells in five randomly selected fields were enumerated, and the counts were averaged. Duplicate wells per condition were tested in three independent experiments. For the invasion assay, except for the pre-coating with $40 \mu \mathrm{L}$ of working Matrigel (Becton, Dickinson and Company, San Diego, CA, USA) on the transwell microfilters, the following procedures of the experiment were the same as those of the cell migration assay. After incubated with indicated time, the cells reaching the lower chamber were measured by the same method as the cell migration assay.

\section{Cell viability assays}

For cell viability assays, $100 \mu \mathrm{L}$ of endometrial stromal cells were seeded in 96 -well dishes at a density of $2 \times 10^{4}$ cells/well. After treated for indicated treatment, $10 \mu \mathrm{L}$ of 3-(4,5-dimethylthiazol-2-yl)-2,5-diphenyltetrazolium bromide (MTT) (Sigma, Belgium) was added into each well and the final concentration is $0.5 \mathrm{mg} / \mathrm{mL}$. After cells were incubated for $4 \mathrm{~h}$ at $37^{\circ} \mathrm{C}$ in the dark, the supernatant was removed and formazan crystals were dissolved by the addition of $150 \mu \mathrm{L} /$ well dimethyl sulfoxide (DMSO) at $37{ }^{\circ} \mathrm{C}$ for $15 \mathrm{~min}$ with gentle agitation. The absorbance intensity was measured at $490 \mathrm{~nm}$ with a microplate reader (Bio-Rad, PA, USA). The percentage of cell viability was calculated as follows: $\%$ cell viability $=$ (mean absorbance in test wells)/(mean absorbance in control wells) $\times 100$.

\section{Wound healing assay}

Briefly, $8 \times 10^{5}$ human endometrial stromal cells were seeded in 6-well plates until the cells grew to $90-95 \%$ confluency. Then a $200 \mu \mathrm{L}$ pathogen-free pipette tip was used to scratch a linear wound through the monolayer across each well. Floating cellular debris was removed by gentle washes with pre-warm PBS and cultured in DMEM/F12 medium with $1 \%$ FBS, following by treated with $15 \mu \mathrm{M}$ GANT-61 (Sigma-Aldrich, USA) or infected with GLI1 shRNA for $48 \mathrm{~h}$. Then the cells were allowed to migrate for a further $48 \mathrm{~h}$. Migration at the wound site was observed and representative images photographed under an inverted microscope (Olympus 600 auto-biochemical analyzer, Tokyo, Japan) at 0 and $48 \mathrm{~h}$ respectively. The healing percentage was calculated using Image-Pro Plus 6.0 software. The cell migration area $=($ width at $0 \mathrm{~h}-$ width at different time points)/width at $0 \mathrm{~h}$. 


\section{Colony formation assay}

After treated with $15 \mu \mathrm{M}$ GANT-61 and infected with GLI1 shRNA or GFP control adenovirus for $48 \mathrm{~h}$, human endometrial stromal cells were routinely trypsinized and seeded in 6-well plates at about 100 cells per well. After a 16-h incubation, cells were continuously cultured in new fresh medium for 14 days to allow colony formation. During colony growth, the culture medium was replaced every 3 days. Then colonies were fixed and stained with crystal violet, and the number of colonies was counted. The colony was counted only if it contained $>50$ cells. Each treatment was carried out in triplicate.

\section{Statistical analysis}

Statistical analyses were carried out with Graphpad Prism (version 8.0; GraphPad Software Inc., CA, USA). Descriptive data are shown as mean \pm standard deviation (SD) from at least three different independent experiments. The Kruskal-Wallis test was used for statistical significance of differences in variables with non-normal distribution. Comparison between two groups was performed by using Student's $t$-test. The one-way analysis of variance (ANOVA) followed by Tukey's post hoc test were used to measure the comparisons between multiple groups in normal distribution. Differences with $\mathrm{P}$ values of $<0.05$ were considered statistically significant.

\section{Results}

\section{Immunobistochemical localization and expression of GLI1 protein in the normal and ectopic endometrium tissues of endometriosis}

To investigate the localization and expression of GLI1 in ovarian endometriosis, sections of different endometrial tissue samples, namely, normal control endometrium and ectopic endometrium of endometriosis patients, were subjected to immunohistochemistry analysis. As can be seen in Figure 1, GLI1 was mainly localized in the cytoplasm of endometrial epithelial cells in normal proliferative endometrium. While in the ectopic endometrium of ovarian endometriosis, GLI1 was observed in both cytoplasm and nuclear in endometrial epithelial and stromal cells. The expression levels of GLI1 in the ectopic endometrium were significantly greater than those in normal endometrium. Moreover, nuclear and cytoplasmic GLI1 protein expression levels were compared in 31 cases normal endometrium and 30 cases ectopic endometrium. Nuclear GLI1 expression was found in 29 ectopic endometrium tissues (96.7\%), while no nuclear expression was observed in all normal endometrium tissues (Table 2). Nonspecific rabbit IgG was used as a negative control and showed no immunostaining. Taken together, the data provided evidence that GLI1 is upregulated in ectopic endometrium of endometriosis.

\section{Elevated GLI1 mRNA and protein expression in ovarian endometriosis tissues}

To further determine whether GLI1 is dysregulated in ovarian endometriosis, we examined the mRNA and protein levels of GLI1 in normal endometrium and ectopic endometrium from patients with endometriosis. Firstly, we analyzed the relative GLI1 mRNA expression in endometrial tissues by qRT-PCR. As shown in Figure 2A, compared with normal endometrium, GLI1 mRNA expression levels were significantly up-regulated in the ectopic endometrium with endometriosis $(\mathrm{P}<0.05)$. Moreover, Western blot assay was performed to detect the expression levels of GLI1. As shown in Figure $2 B$ and $C$, the data revealed that increased total and nuclear protein expression of GLI1 was present in ovarian endometriosis samples compared with normal endometrium from healthy control women $(\mathrm{P}<0.05)$. Taken together, these results suggested that GLI1 is up-regulated in ectopic endometrium and GLI1 might be involved in the pathological process.

\section{Morphology and identification of primary human endometrial stromal cells}

Vimentin and E-cadherin are the specific markers of human endometrial stromal cells and human endometrial glandular epithelial cells, respectively. As shown in Figure 3, human endometrial stromal cells displayed long-spindle and typical fibroblast-like shapes with positively expressing mesenchymal specific markers Vimentin and negatively expressing epithelial specific marker E-cadherin. The purity of primary human endometrial stromal cells in isolated cells was $>95 \%$.

\section{GLI1 adenovirus shRNA infection efficiency}

The aberrantly increased expression of GLI1 in ovarian endometriosis tissues prompted us to explore the potential 
Control

GLI1

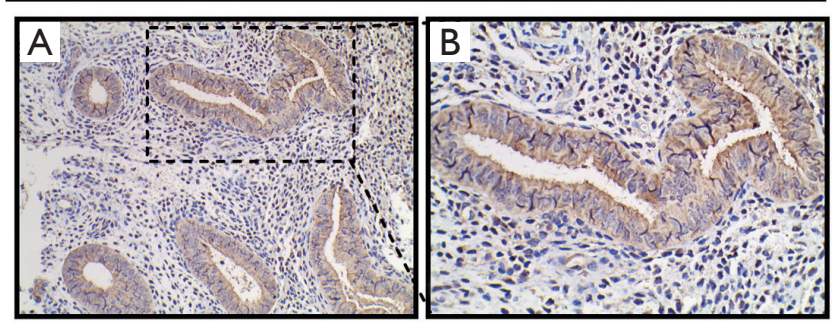

$\lg G$

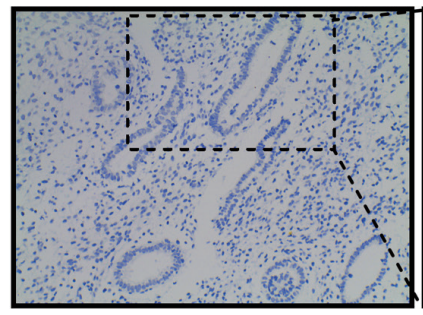

$200 x$

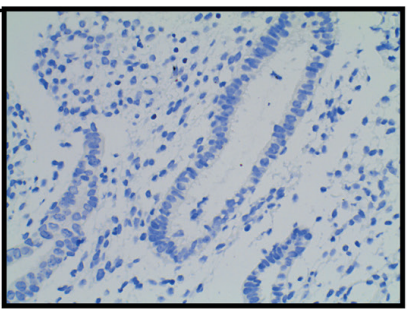

$400 x$

Endometriosis

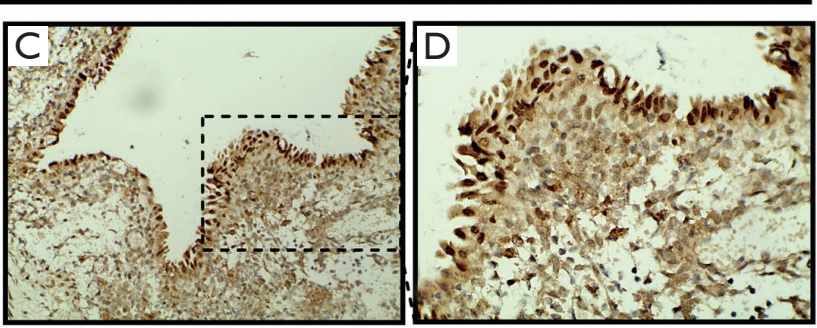

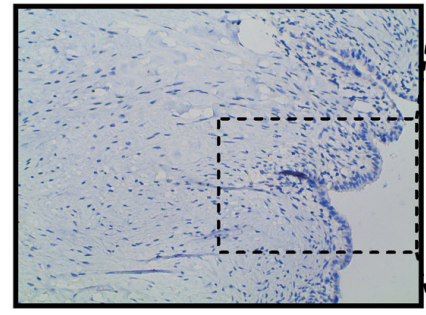

$200 x$

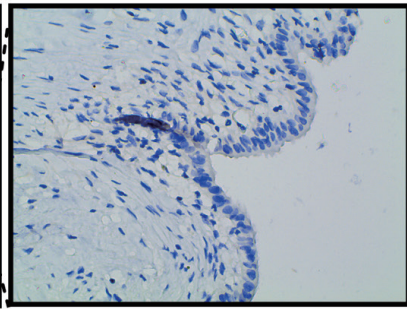

$400 x$

Figure 1 Glioma associated oncogene 1 (GLI1) localization and expression in different groups of endometrium. Representative images of immunohistochemical analysis of GLI1 in normal endometrium (A,B) and ectopic endometrium (C,D). Normal IgG is used as negative control. Photographs were taken at magnifications of 200× (left panels) and 400× (right panels) respectively.

Table 2 Immunostaining score and percentage of cells with GLI1positive nuclear or cytoplasm in normal endometrium and ectopic endometrium (GLI1 immunostaining score)

\begin{tabular}{lc}
\hline Endometrium & Number (\%) \\
\hline Normal endometrium & 31 \\
Cases & $0(0)$ \\
Nucleus & $18(58.1)$ \\
Cytoplasm & $13(41.9)$ \\
Negative & $2.640 \pm 1.313$ \\
Immunostaining score ${ }^{\star \star}$ & \\
Ectopic endometrium & 30 \\
Cases & $21(70.0)$ \\
Nucleus & $8(26.7)$ \\
Nucleus and cytoplasm & $1(3.3)$ \\
Negative & $11.742 \pm 1.015$ \\
Immunostaining score
\end{tabular}

*, normal endometrium nuclear GLI1 expression versus ectopic endometrium nuclear GLI1 expression; ${ }^{*}$, normal endometrium nuclear plus cytoplasm GLI1 expression versus ectopic endometrium nuclear plus cytoplasm GLI1 expression. *, $\mathrm{P}<0.05$; ${ }^{*}, \mathrm{P}<0.01$. All data are expressed as mean $\pm \mathrm{SD}$. Statistical significance (Student's t-test analysis). molecular mechanism of GLI1. To manipulate the GLI1 levels in human endometrial stromal cells, adenoviral scramble shRNA and adenovirus shRNA against GLI1 were infected into human endometrial stromal cells and then assessed GLI1 expression 24 hours later. We first evaluate the infection efficiency by immunofluorescence. Figure $4 \mathrm{~A}$ shows that more than $95 \%$ of the maximum infection efficiency was obtained with 24 hours co-incubation and the number of positive cells increases with the co-incubation time to a maximum at $48 \mathrm{~h}$ of infection. Then, the infection efficiency was further confirmed by qRT-PCR and western blotting analysis. As shown in Figure 4B,C,D, compared with scramble shRNA, the decrease in mRNA and protein expression of GLI1 was minimal when infected with GLI1 shRNA-2, and a strong knockdown was observed with GLI1 shRNA-1 $(\mathrm{P}<0.05)$. Therefore, GLI1 shRNA-1 was further used in subsequent experiments. These data indicated that GLI1 shRNA effectively suppressed mRNA and protein expressions of GLI1 in human endometrial stromal cells.

\section{Effect of GLI1 on human endometrial stromal cell migration}

To determine whether GLI1 influences cell migration 


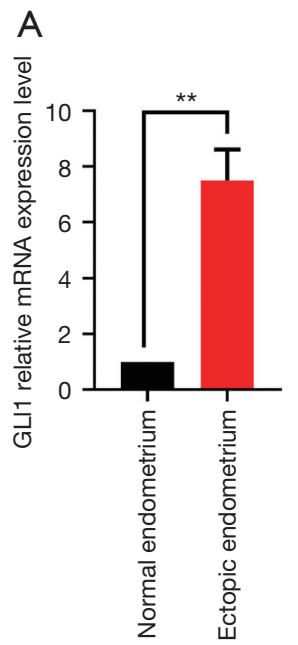

B

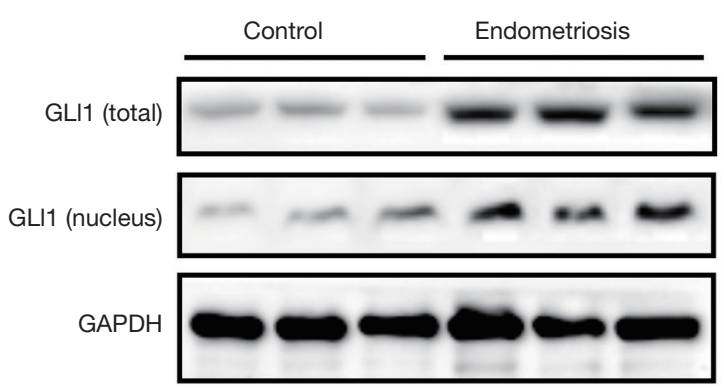

C

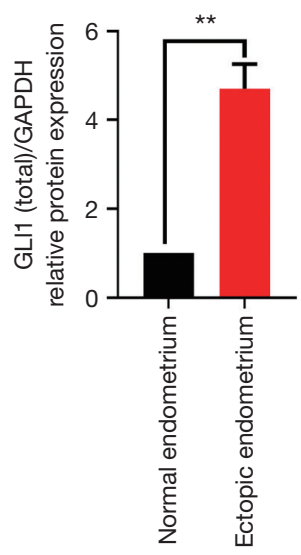

$\mathrm{D}$

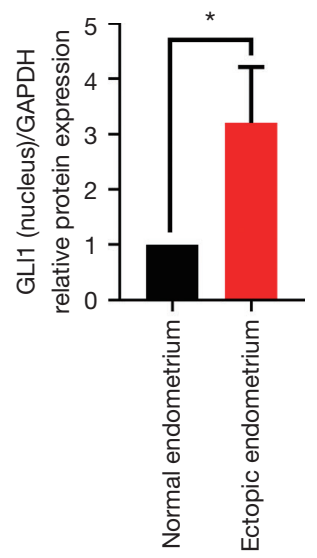

Figure 2 The expression levels of GLI1 was increased in ectopic endometrium of endometriosis patients. (A) Expression of mRNA encoding GLI1 gene in normal endometrium and ovarian ectopic endometriotic lesions as detected by qRT-PCR; (B) representative Western blots of GLI1 protein from normal endometrium and ectopic endometrium; (C) the quantitative comparison of the fold difference in the expression of GLI1 protein. The data are presented as the means $\pm \mathrm{SD}$ of three independent experiments ( ${ }^{*}, \mathrm{P}<0.05 ;{ }^{* *}, \mathrm{P}<0.01$ by Student's $t$-test).

Light scopy
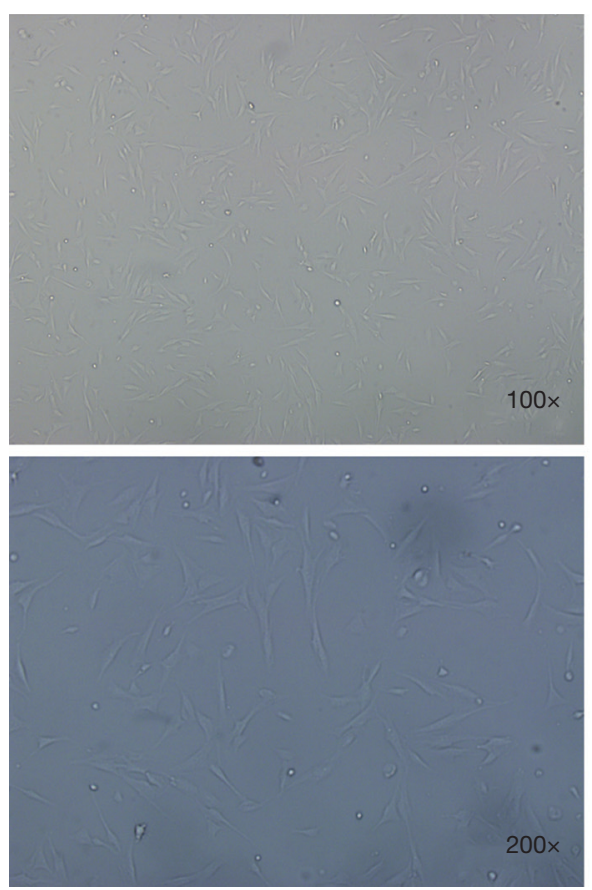

E-cadherin
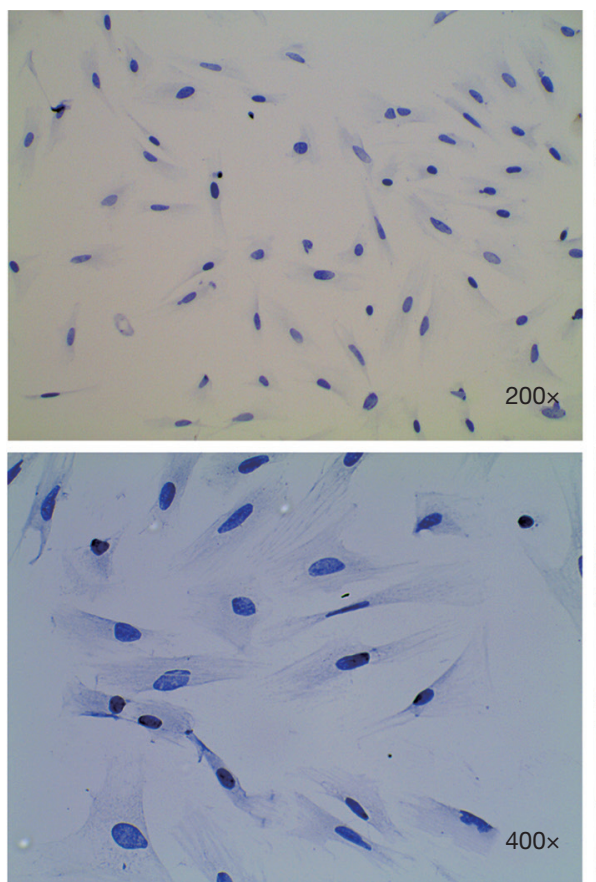

Vimentin

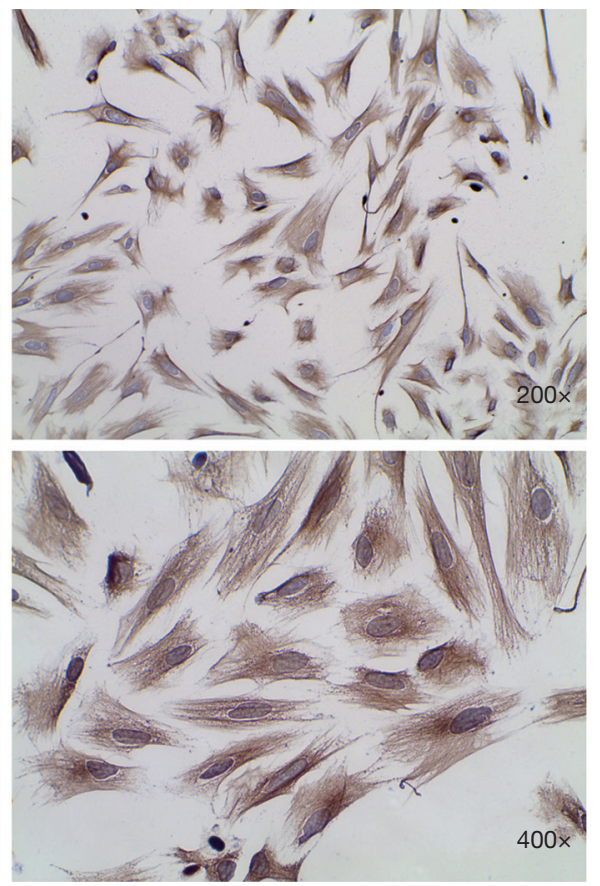

Figure 3 Identification of the primary human endometrial stromal cells. Representative of morphology of cultured primary endometrial stromal cells. Immunocytochemistry staining of E-cadherin and vimentin protein in endometrial stromal cells. For morphology images, photographs were taken at magnifications of $100 \times$ (upper panels) and $200 \times$ (lower panels). For immunocytochemistry images, photographs were taken at $200 \times$ (left panels) and $400 \times$ (right panels), respectively. 
A

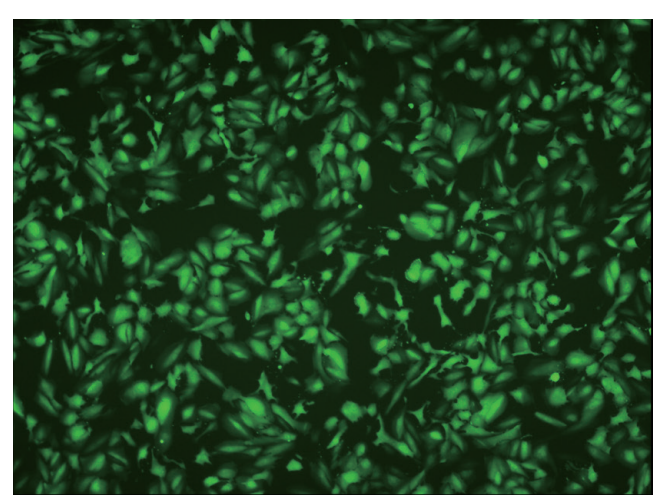

C

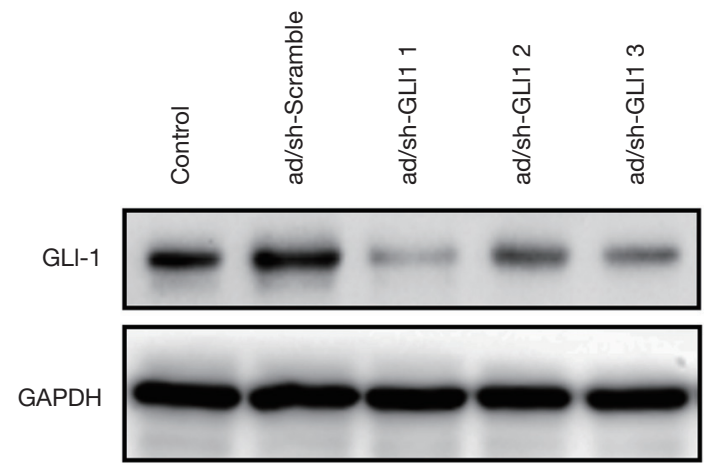

B

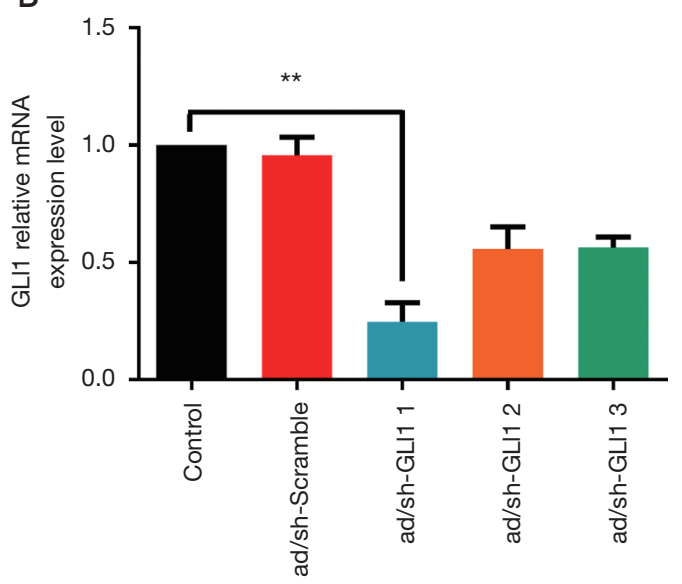

D

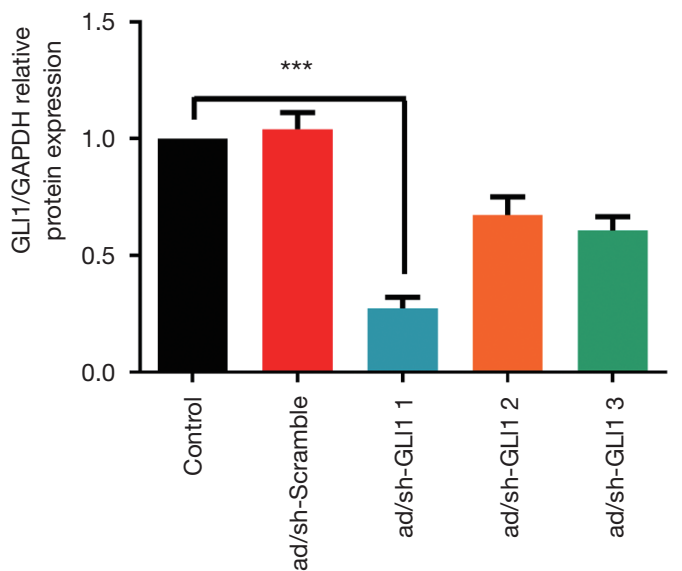

Figure 4 The infection efficiency of GLI1 shRNA. (A) Human endometrial stromal cells were infection with GLI1 shRNA adenovirus, and the expression of GFP was observed with a fluorescence microscope after 48 h. Photographs were taken at magnifications of 200x; (B) the expression of GLI1 mRNA were measured by quantitative real-time PCR; (C) representative Western blots of GLI1 protein from human endometrial stromal cells which were infected with adenovirus; (D) the quantitative comparison of the fold difference in the expression of GLI1 protein. The data are presented as the means $\pm \mathrm{SD}$ of three independent experiments ${ }^{*}, \mathrm{P}<0.05 ;{ }^{* *}, \mathrm{P}<0.01 ;{ }^{* * *}, \mathrm{P}<0.001$ by one-way ANOVA).

potentiality, human endometrial stromal cells were treated with GLI1 antagonist GANT-61 $(15 \mu \mathrm{M})$ and infected with adenovirus shRNA against GLI1, respectively. GANT-61 is a cell-permeable hexahydropyrimidine compound which selectively inhibits GLI1 and GLI2 transcription factors in the Hedgehog signaling pathway (21). The migratory potential of these cells was detected by wound healing assay and transwell migration assay, respectively. As shown in Figure $5 A, B$, the results of wound-healing assays demonstrated that inhibition of GLI1 by GANT-61 and GLI1 shRNA significantly attenuated the motility ability of human endometrial stromal cells $(\mathrm{P}<0.05)$. Moreover, we found that compared with control and scramble shRNA group, the inhibition of GLI1 also attenuated human endometrial stromal cells migration abilities (Figure 5C,D, $\mathrm{P}<0.05)$. Taken together, these findings indicated that GLI1 could enhance human endometrial stromal cell migration.

\section{Effect of GLI1 on human endometrial stromal cell invasion}

To further examine the role of GLI1 in regulating human 


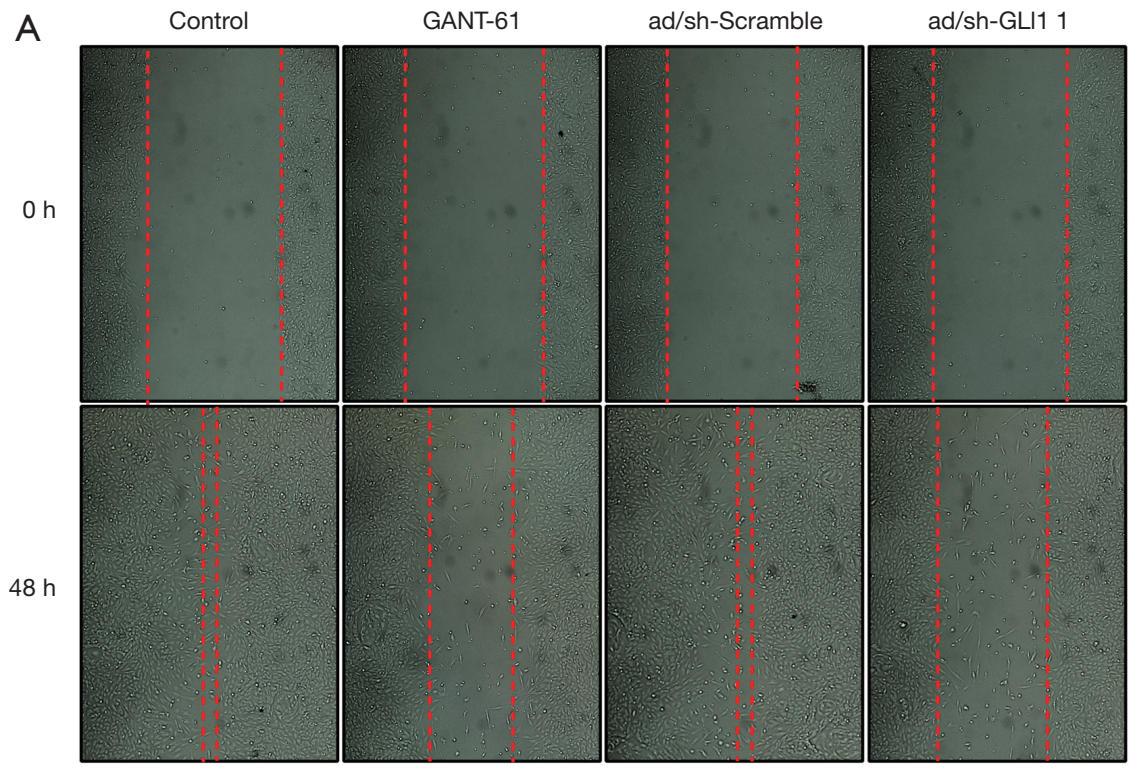

B

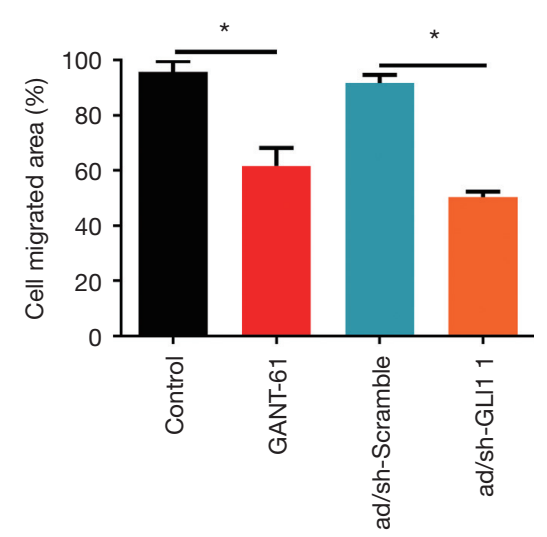

C
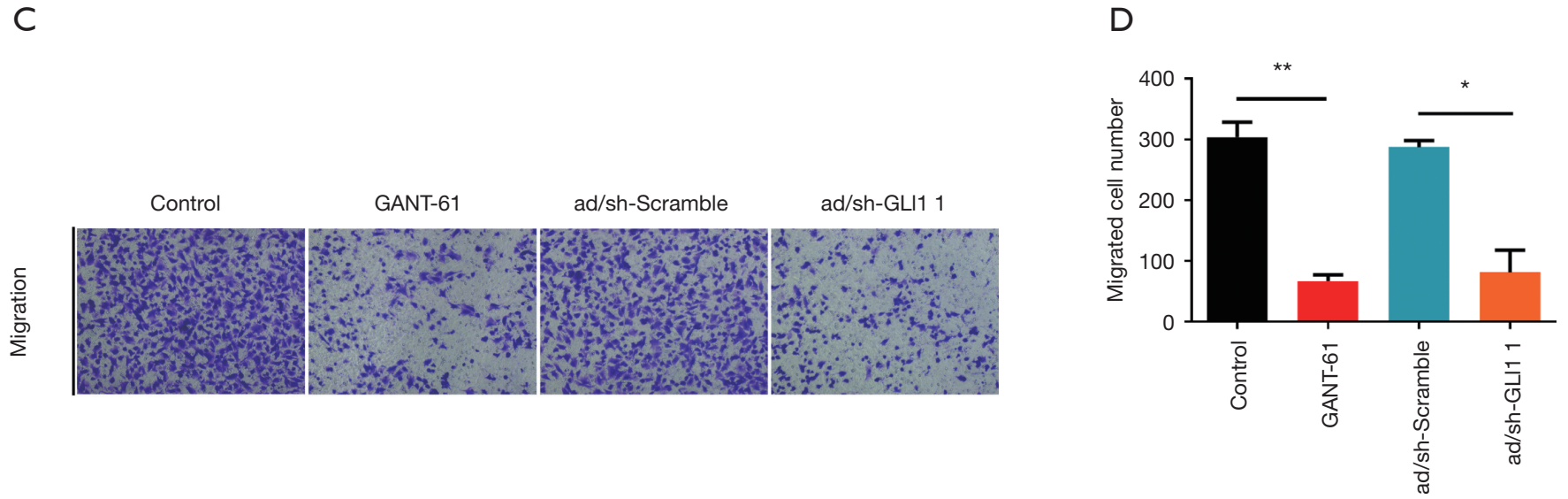

Figure 5 Effects of GLI1 on human endometrial stromal cells migration. (A) Representative bright-field photographs (magnification: 100x) of migrated area at $48 \mathrm{~h}$ after indicated treatment; (B) quantitative assessment of the migrated area of endometrial stromal cells; (C) representative photographs of migration of control, GANT-61 treated (15 $\mu \mathrm{M})$, ad/sh-Scramble treated and ad/sh-GLI1 1 treated endometrial stromal cells (magnification: 200x); (D) quantitative assessment of the number of endometrial stromal cells migrated to the lower chamber. The data are presented as the means $\pm \mathrm{SD}$ of three independent experiments $\left({ }^{*}, \mathrm{P}<0.05 ;{ }^{* *}, \mathrm{P}<0.01\right.$ by one-way ANOVA).

endometrial stromal cell invasion, we performed Transwell matrigel invasion chamber assays. As shown in Figure $6 \mathrm{~A}$ and $B$, the number of invading cells was significantly decreased in the group treated with GLI1 shRNA or GANT-61 $(15 \mu \mathrm{M})$ when compared with that in control and scramble shRNA group $(\mathrm{P}<0.05)$. Our findings indicated that GLI1 could promote human endometrial stromal cell invasion.

\section{Effect of GLI1 on human endometrial stromal cell proliferation}

To further evaluate the functional role of GLI1 in cell proliferation, MTT assay was used to evaluate cell proliferation in GLI1-deficient cells. As shown in Figure 7A, cell viability of the GANG-61 $(15 \mu \mathrm{M})$ treated group and GLI1 shRNA infected group decreased significantly when compared with the control group and scramble 
A Control

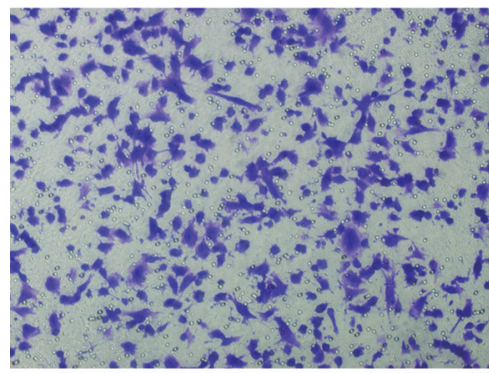

ad/sh-Scramble

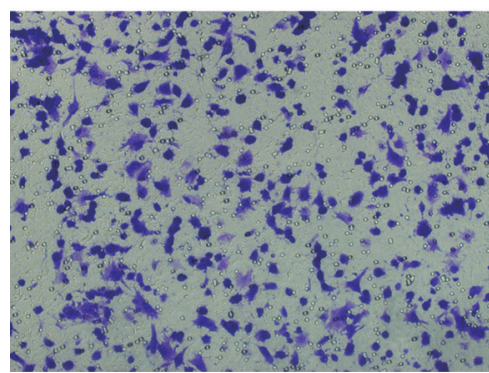

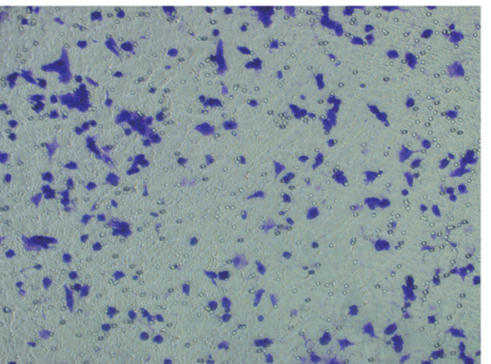

ad/sh-GLI1 1

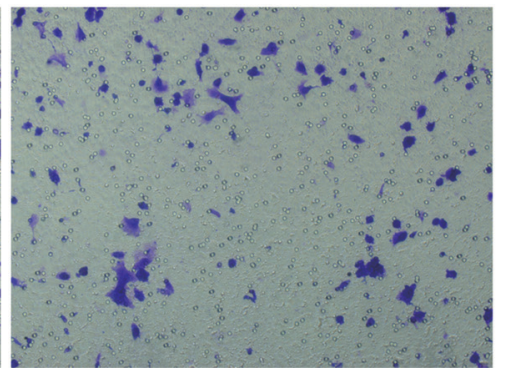

B

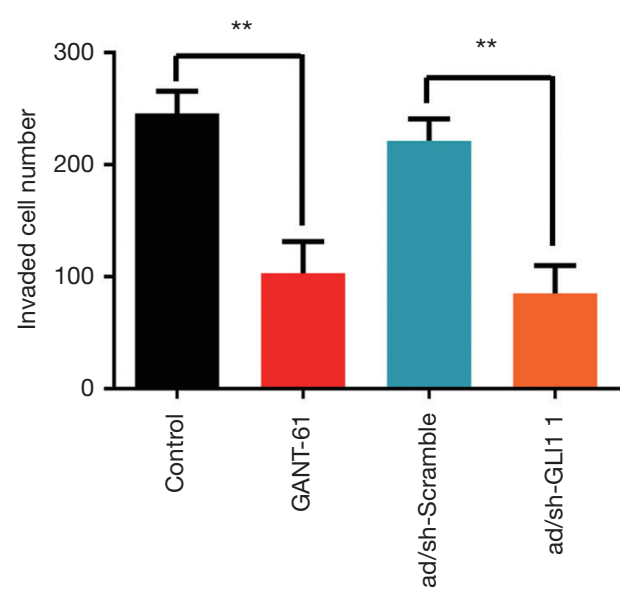

Figure 6 Effects of GLI1 on human endometrial stromal cells invasion. (A) Representative photographs of invasion of control, GANT-61 treated $(15 \mu \mathrm{M}), \mathrm{ad} / \mathrm{sh}-\mathrm{Scramble}$ treated and ad/sh-GLI1 1 treated endometrial stromal cells; (B) quantitative assessment of the number of endometrial stromal cells invaded to the lower chamber. The data are presented as the means \pm SD of three independent experiments $\left({ }^{* *}\right.$, $\mathrm{P}<0.01$ by one-way ANOVA). Photographs were taken at magnifications of $200 \times$.

shRNA group $(\mathrm{P}<0.05)$, indicating that depletion of GLI1 attenuates cell viability of human endometrial stromal cells. Moreover, the colony formation assay showed that compared to negative controls group and scramble shRNA group, downregulation of GLI1 by GANT-61 $(15 \mu \mathrm{M})$ or GLI1 shRNA significantly inhibited colony formation in human endometrial stromal cells $(\mathrm{P}<0.05)$ (Figure $7 B, C)$. Collectively, these results demonstrated that upregulation of GLI1 can promote proliferation of human endometrial stromal cells.

\section{Effect of GLI1 on MMP-2 and MMP-9 expressions in buman endometrial stromal cell}

As the major members of the matrix metalloproteinases (MMPs) family, MMP-2 and MMP-9 are believed to play a vital role in the process of extracellular matrix (ECM) degradation and be tightly associated with invasion and metastasis of endometriosis $(22,23)$. Here, we evaluate whether decreased migratory and invasive abilities of GLI1 downregulated cells were associated with MMP-2 and MMP-9. As shown in Figure 8, inhibition of GLI1 by GANT-61 $(15 \mu \mathrm{M})$ or GLI1 shRNA significantly decreased MMP-2 and MMP-9 mRNA and protein expressions in human endometrial stromal cells $(\mathrm{P}<0.05)$. These findings suggest that elevation of GLI1 may contribute to cell migration and invasion via upregulation of MMP2 and MMP2 in human endometrial stromal cells.

\section{Discussion}

In the present study, we demonstrate for the first time that GLI1 mRNA and protein expression level was significantly higher in the ectopic endometrium of endometriosis patients than that in the normal endometrium. In addition, immunohistochemical staining intensity of GLI1 was higher in the nucleus of epithelial and stromal cells in the ectopic endometrium when compared with normal endometrium. Using endometrial stromal primary cells as a model, the knockdown of GLI1 resulted in reduced cell migration, invasion and proliferation potentiality. Moreover, we found that GLI1 may facilitate cell migration and invasion by 
A

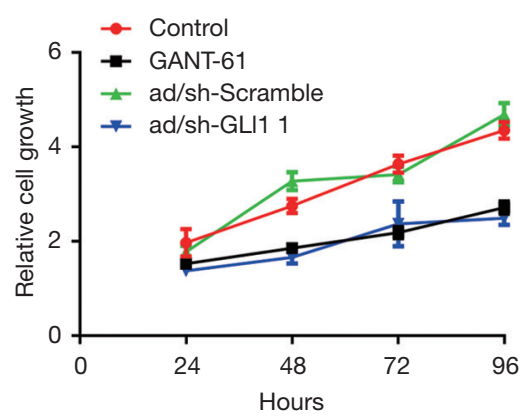

B

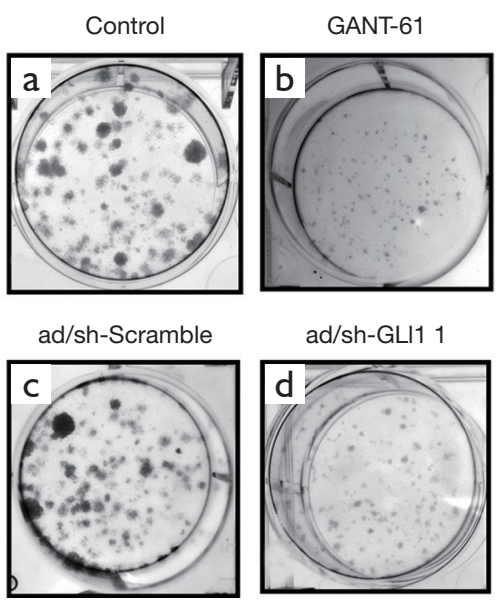

C

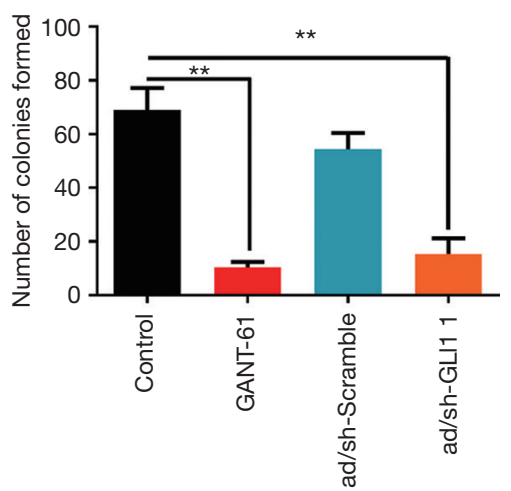

Figure 7 Effects of GLI1 on human endometrial stromal cells proliferation. (A) Cell growth of endometrial stromal cells treated with GANT-61 (15 $\mathrm{MM}$ ), ad/sh-Scramble or ad/sh-GLI1 1 was detected by MTT assay; (B) representative images of colonies formed in HESCs treated with GANT-61, ad/sh-Scramble or ad/sh-GLI1 1 [a, control group; b, GANT-61 treated group (15 $\mu \mathrm{M})$; c, ad/sh-Scramble group; d, ad/sh-GLI1 1 group]; (C) quantitative assessment of the number of colonies formed in endometrial stromal cells. The data are presented as the means $\pm \mathrm{SD}$ of three independent experiments ${ }^{* *}, \mathrm{P}<0.01$ by one-way ANOVA).

A

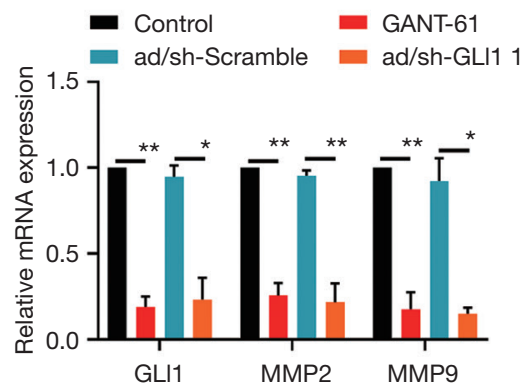

B

$B$

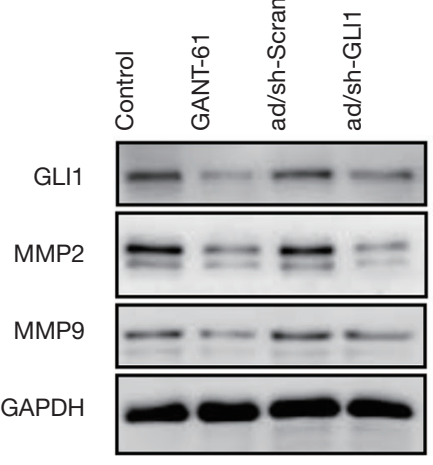

C

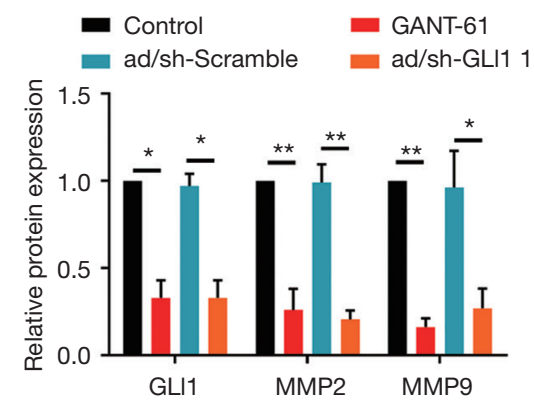

Figure 8 Effects of GLI1 on the expression of MMP2 and MMP9. (A) Human endometrial stromal cells were treated with GANT-61 (15 $\mu M)$, ad/sh-Scramble or ad/sh-GLI1 1, and then the expression of MMP2 and MMP9 mRNA were measured by quantitative real-time PCR; (B) representative Western blots of GLI1, MMP2 and MMP9 protein from human endometrial stromal cells which were treated with GANT-61 (15 $\mathrm{MM})$, ad/sh-Scramble or ad/sh-GLI1 1; (C) the quantitative comparison of the fold difference in the expression of GLI1, MMP2 and MMP9 protein. The data are presented as the means \pm SD of three independent experiments $\left({ }^{*}, \mathrm{P}<0.05 ;{ }^{* *}, \mathrm{P}<0.01\right.$ by one-way ANOVA).

activating MMP2 and MMP9. These findings suggested that GLI1 may participate in the development and progression of endometriosis by regulating endometrial cell migration, invasion and proliferation through regulating the expression of MMP2 and MMP9.

Endometriosis is a very common disorder and the process of endometriosis development shares striking features with malignancy disease, such as migration, invasion, abnormal proliferation and recurrence $(1,24)$. Despite decades of extensive clinical and scientific research into the pathogenesis of endometriosis, the exact aetiology of this enigmatic disease remains complex and controversial (25). 
Emerging data have proposed that aberrant expression of several genes/proteins could modulate and facilitate the growth of ectopic endometrial lesions $(26,27)$. GLI1, a core mediator of Hh signaling pathway has previously been implicated in the development and progression of several different human cancers such as breast cancer and endometrial cancer, suggesting that GLI1 may facilitate the progression of these reproductive malignancies $(14,28,29)$. Indeed, GLI1 has been mechanistically linked to all of the above mentioned pathophysiologically relevant processes and may be a contributing factor to the pathogenesis of endometriosis. For example, Heard et al. reported that Krüppel-like factor 9 (KLF9) deficiency in uterine endometrial cells promotes ectopic lesion establishment associated with activated Hedgehog signaling in a mouse model of endometriosis (30). What's more, previous studies have also investigated the expression of GLI1 in the normal endometrium and eutopic endometrium of patients with ovarian endometriosis. He et al. reported that upregulation of GLI1 mRNA expression and immunity intensity in eutopic endometrium tissues of patients with ovarian endometriosis compared with in the normal control endometrium (16). However, they detected the GLI1 expression levels only in eutopic endometrium of ovarian endometriosis patients, but not in ectopic endometrium tissues, which were more accurate to reflect the GLI1 expression in human endometriosis. In this study, by thorough examination of ovarian endometriosis samples, we found that expression levels of GLI1 were significantly upregulated in ovarian endometriosis samples when compared with normal endometrium. Our present findings add weight to their observation and provide further evidence that elevated GLI1 expression in ectopic endometrium was significantly involved in the pathogenesis of endometriosis.

It has been well established that GLI1 is a primary downstream effector of the Shh signaling pathway crucial for tumorigenesis by controlling migration, invasion, apoptosis and proliferation (31). In 2014, Chen et al. found that down-regulation of GLI1 inhibits hepatocellular carcinoma cell migration and invasion (9). In colon cancer, upregulation of GLI1 protein expression was observed and the GLI1 level in colon cancer cells is correlated with increased lymph node metastasis (32). In addition, Mori el al. reported that shh signaling pathway specific inhibitor cyclopamine may inhibit the cell proliferation and migration by suppressing the expression of GLI1 in human esophageal squamous cell carcinoma cells (33).
Therefore, GLI1 was further knocked down to investigated its role in regulating human endometrial stromal cells migration, invasion and proliferation. Notably, our results showed that the application of GANT-61, which is a smallmolecule antagonist of GLI1, and lentivirus shRNA against GLI1 significantly reduced the migration, invasion and proliferation potentiality of human endometrial stromal cells.

The migration, invasion and metastasis of malignant cancer cells is a complicated and multi-stage procedure involving dissolution of basement membranes as an early step in the metastatic process (34). MMPs are vital family of proteolytic enzymes that have the abilities to degrade most of the ECM components when they are activated (35). Previous studies have demonstrated that MMPs are involved in multiple pathophysiological processes in the human body, including cell adhesion, angiogenesis, tumor invasion, and metastasis (36,37). Among the MMPs, MMP2 and MMP9 are especially important for tumor invasion and metastasis. Webb et al. reported that inhibition of MMP2 and MMP9 decreases cellular migration, and angiogenesis in in vitro models of retinoblastoma (38). Indeed, an upregulation of several MMPs has also been linked to the pathogenesis of endometriosis (39). Further studies have suggested that MMP2 and MMP9 are tightly associated with the formation of endometriosis (40). Li et al. demonstrated that

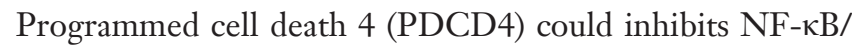
MMP2/MMP9 signal pathway and thereby decreased migration and invasion of human endometrial cells (41). Moreover, previous researches also indicated that GLI1 could take part in cancer cell migration and invasion process by modulating the expression of MMP2 and MMP9. Nagai et al. reported that GLI1 contributes to the invasiveness of pancreatic cancer cell through MMP-9 activation (42). In hepatocellular carcinoma, down-regulation of GLI1 suppresses cell migration and invasion likely through inhibiting expressions and activations of MMP2/9 and blocking EMT process (9). Treatment of vemurafenibresistant human melanoma cells with the GLI1 inhibitor GANT-61 led to decreased invasion of the melanoma cells and was associated with a decrease in metalloproteinase (MMP2/9) expression (43). Consistent with previous studies, our present data demonstrated that inhibition of GLI1 expression by GANT-61 and GLI1 shRNA resulted in decreased expression of MMP2 and MMP9 in human endometrial stromal cells. Taken together, these results suggest that inhibition of GLI1 could attenuate cellular migration and invasion potentiality through direct down- 


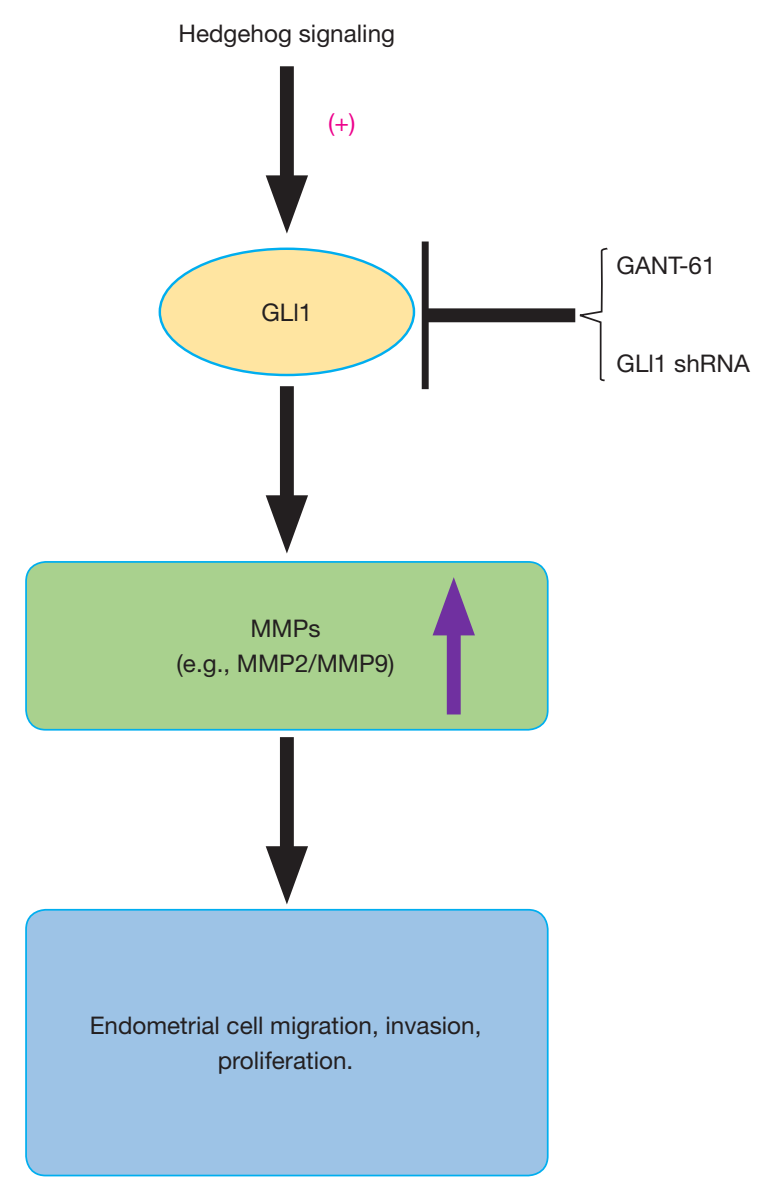

Figure 9 Proposed model illustrating the effect of GLI1 on endometrial stromal cells migration, invasion and proliferation. + indicates that the Hedgehog signaling is activated.

regulating the expression of MMP2 and MMP9.

However, on a cautionary note, there are some limitations to our current study that should be pointed out. First, we only collected normal proliferative stage endometrial tissues. Second, eutopic endometrium from patients with ovarian endometriosis was not investigated in our present study. These limitations may reduce the interpretable power of the current findings. Therefore, normal and eutopic endometrium from patients with endometriosis across the full menstrual cycle should be further investigated in our future research.

\section{Conclusions}

In conclusion, this is the first study to demonstrate that GLI1 may be associated with the progression of endometriosis by modulating the migration, invasion and proliferation potentiality of human endometrial stromal cells through regulation of MMP2 and MMP9 expression (Figure 9). Our research indicates an important role of GLI1 in the pathogenesis and development of endometriosis. Therefore, understanding the GLI1 gene is a key to improve our understanding of the pathogenesis of endometriosis as well as developing new and more effective therapeutic strategies for treating endometriosis.

\section{Acknowledgments}

Funding: This work was supported by the grants from the National Natural Science Foundation of China (Grant No. 8197061339 to Yi Liu) the grants from the Medjaden Academy and Research Foundation for Young Scientists (grant MJR20190005 to H Liu), the Program of Excellent Doctoral (Postdoctoral) of Zhongnan Hospital of Wuhan University (Grant No. ZNYB2019009) and the NIH Award (Grant NIH HD076257 to Z Zhang).

\section{Footnote}

Conflicts of Interest: The authors have no conflicts of interest to declare.

Ethical Statement: The authors are accountable for all aspects of the work in ensuring that questions related to the accuracy or integrity of any part of the work are appropriately investigated and resolved. This study was approved by the Local Ethics Committee of Tongji Medical College, Huazhong University of Science (IORG No: IORG0003571) and written informed consent was obtained from all patients.

\section{References}

1. Vercellini P, Vigano P, Somigliana E, et al. Endometriosis: pathogenesis and treatment. Nat Rev Endocrinol 2014;10:261-75.

2. Foti PV, Farina R, Palmucci S, et al. Endometriosis: clinical features, MR imaging findings and pathologic correlation. Insights Imaging 2018;9:149-72.

3. Rocha ALL, Reis FM, Taylor RN. Angiogenesis and endometriosis. Obstet Gynecol Int 2013;2013:859619.

4. Delbandi AA, Mahmoudi M, Shervin A, et al. Eutopic and ectopic stromal cells from patients with endometriosis exhibit differential invasive, adhesive, and proliferative behavior. Fertil Steril 2013;100:761-9. 
5. Ingham PW, McMahon AP. Hedgehog signaling in animal development: paradigms and principles. Genes \& development 2001;15:3059-87.

6. Gorojankina T. Hedgehog signaling pathway: a novel model and molecular mechanisms of signal transduction. Cell Mol Life Sci 2016;73:1317-32.

7. Briscoe J, Therond PP. The mechanisms of Hedgehog signalling and its roles in development and disease. Nat Rev Mol Cell Biol 2013;14:416-29.

8. Fiaschi M, Rozell B, Bergström Å, et al. Development of mammary tumors by conditional expression of GLI1. Cancer Res 2009;69:4810-7.

9. Chen JS, Li HS, Huang JQ, et al. Down-regulation of Gli-1 inhibits hepatocellular carcinoma cell migration and invasion. Mol Cell Biochem 2014;393:283-91.

10. Sun Y, Wang Y, Fan C, et al. Estrogen promotes stemness and invasiveness of ER-positive breast cancer cells through Gli1 activation. Mol Cancer 2014;13:137.

11. Ke Z, Caiping S, Qing Z, et al. Sonic hedgehog-Gli1 signals promote epithelial-mesenchymal transition in ovarian cancer by mediating PI3K/AKT pathway. Med Oncol 2015;32:368.

12. Bassi MA, Podgaec S, Dias Júnior JA, et al. Bowel endometriosis: a benign disease? Rev Assoc Med Bras (1992) 2009;55:611-6.

13. Kim KH, Kim JM, Choi YL, et al. Expression of sonic hedgehog signaling molecules in normal, hyperplastic and carcinomatous endometrium. Pathol Int 2009;59:279-87.

14. Liao X, Siu MK, Au CW, et al. Aberrant activation of hedgehog signaling pathway contributes to endometrial carcinogenesis through beta-catenin. Mod Pathol 2009;22:839-47.

15. Wei Q, Levens ED, Stefansson L, et al. Indian Hedgehog and its targets in human endometrium: menstrual cycle expression and response to CDB-2914. J Clin Endocrinol Metab 2010;95:5330-7.

16. He Y, Guo Q, Cheng Y, et al. Abnormal activation of the sonic hedgehog signaling pathway in endometriosis and its diagnostic potency. Fertil Steril 2018;110:128-36.e2.

17. Liu H, Du Y, Zhang Z, et al. Autophagy contributes to hypoxia-induced epithelial to mesenchymal transition of endometrial epithelial cells in endometriosis. Biol Reprod 2018;99:968-81.

18. Remmele W, Schicketanz KH. Immunohistochemical determination of estrogen and progesterone receptor content in human breast cancer. Computer-assisted image analysis (QIC score) vs. subjective grading (IRS). Pathol Res Pract 1993;189:862-6.
19. Liu H, Zhang Z, Xiong W, et al. Hypoxia-inducible factor- $1 \alpha$ promotes endometrial stromal cells migration and invasion by upregulating autophagy in endometriosis. Reproduction 2017;153:809-20.

20. Liu H, Zhang Z, Xiong W, et al. Long non-coding RNA MALAT1 mediates hypoxia-induced pro-survival autophagy of endometrial stromal cells in endometriosis. J Cell Mol Med 2019;23:439-52.

21. Li J, Cai J, Zhao S, et al. GANT61, a GLI inhibitor, sensitizes glioma cells to the temozolomide treatment. J Exp Clin Cancer Res 2016;35:184.

22. Lee J, Banu SK, Subbarao T, et al. Selective inhibition of prostaglandin $\mathrm{E} 2$ receptors $\mathrm{EP} 2$ and $\mathrm{EP} 4$ inhibits invasion of human immortalized endometriotic epithelial and stromal cells through suppression of metalloproteinases. Mol Cell Endocrinol 2011;332:306-13.

23. Jabłońska-Trypuć A, Matejczyk M, Rosochacki S. Matrix metalloproteinases (MMPs), the main extracellular matrix $(\mathrm{ECM})$ enzymes in collagen degradation, as a target for anticancer drugs. J Enzyme Inhib Med Chem 2016;31:177-83.

24. Anglesio MS, Papadopoulos N, Ayhan A, et al. CancerAssociated Mutations in Endometriosis without Cancer. N Engl J Med 2017;376:1835-48.

25. Czyzyk A, Podfigurna A, Szeliga A, et al. Update on endometriosis pathogenesis. Minerva Ginecologica 2017;69:447-61.

26. Montgomery GW, Nyholt DR, Zhao ZZ, et al. The search for genes contributing to endometriosis risk. Hum Reprod Update 2008;14:447-57.

27. Rai P, Kota V, Deendayal M, et al. Differential proteome profiling of eutopic endometrium from women with endometriosis to understand etiology of endometriosis. J Proteome Res 2010;9:4407-19.

28. Liu X, Zhao T, Bai X, et al. LOC101930370/MiR-1471 Axis Modulates the Hedgehog Signaling Pathway in Breast Cancer. Cell Physiol Biochem 2018;48:1139-50.

29. Feng YZ, Shiozawa T, Miyamoto T, et al. Overexpression of hedgehog signaling molecules and its involvement in the proliferation of endometrial carcinoma cells. Clin Cancer Res 2007;13:1389-98.

30. Heard ME, Simmons CD, Simmen FA, et al. Kruppel-like factor 9 deficiency in uterine endometrial cells promotes ectopic lesion establishment associated with activated notch and hedgehog signaling in a mouse model of endometriosis. Endocrinology 2014;155:1532-46.

31. Shahi MH, Rey JA, Castresana JS. The sonic hedgehogGLI1 signaling pathway in brain tumor development. 
Expert Opin Ther Targets 2012;16:1227-38.

32. Ding YL, Zhou Y, Xiang L, et al. Expression of gliomaassociated oncogene homolog 1 is associated with invasion and postoperative liver metastasis in colon cancer. Int $\mathrm{J}$ Med Sci 2012;9:334-8.

33. Mori Y, Okumura T, Tsunoda S, et al. Gli-1 expression is associated with lymph node metastasis and tumor progression in esophageal squamous cell carcinoma. Oncology 2006;70:378-89.

34. Massagué J, Batlle E, Gomis RR. Understanding the molecular mechanisms driving metastasis. Mol Oncol 2017;11:3-4.

35. Singh D, Srivastava SK, Chaudhuri TK, et al. Multifaceted role of matrix metalloproteinases (MMPs). Front Mol Biosci 2015;2:19.

36. Brown GT, Murray GI. Current mechanistic insights into the roles of matrix metalloproteinases in tumour invasion and metastasis. J Pathol 2015;237:273-81.

37. Song YH, Shon SH, Shan M, et al. Adipose-derived stem cells increase angiogenesis through matrix metalloproteinase-dependent collagen remodeling. Integr Biol (Camb) 2016;8:205-15.

38. Webb AH, Gao BT, Goldsmith ZK, et al. Inhibition of

Cite this article as: Liu H, Zhang W, Wang L, Zhang Z, Xiong W, Zhang L, Fu T, Li X, Chen Y, Liu Y. GLI1 is increased in ovarian endometriosis and regulates migration, invasion and proliferation of human endometrial stromal cells in endometriosis. Ann Transl Med 2019;7(22):663. doi: 10.21037/ atm.2019.10.76
MMP-2 and MMP-9 decreases cellular migration, and angiogenesis in in vitro models of retinoblastoma. BMC Cancer 2017;17:434.

39. May KE, Villar J, Kirtley S, et al. Endometrial alterations in endometriosis: a systematic review of putative biomarkers. Hum Reprod Update 2011;17:637-53.

40. Malvezzi H, Aguiar VG, Paz CC, et al. Increased circulating MMP-2 levels in infertile patients with moderate and severe pelvic endometriosis. Reprod Sci 2013;20:557-62.

41. Li Y, Wang X, Wang X, et al. PDCD4 suppresses proliferation, migration, and invasion of endometrial cells by inhibiting autophagy and NF-kappaB/MMP2/MMP9 signal pathway. Biol Reprod 2018;99:360-72.

42. Nagai S, Nakamura M, Yanai K, et al. Gli1 contributes to the invasiveness of pancreatic cancer through matrix metalloproteinase-9 activation. Cancer Sci 2008;99:1377-84.

43. Faião-Flores F, Alves-Fernandes DK, Pennacchi PC, et al. Targeting the hedgehog transcription factors GLI1 and GLI2 restores sensitivity to vemurafenib-resistant human melanoma cells. Oncogene 2017;36:1849-61. 


\section{Supplementary}

Table S1 Commercial sources and characteristics of antibodies used

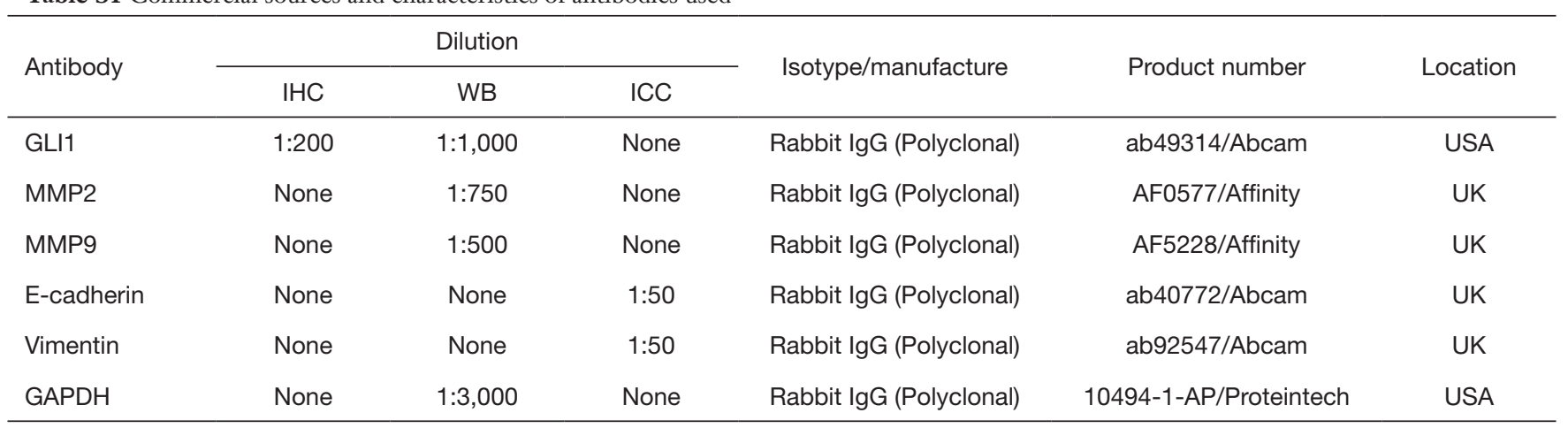

Table S2 Primer sequences used for RT-PCR

\begin{tabular}{|c|c|c|c|c|c|}
\hline Gene name & Primer & Sequence $\left(5^{\prime}-3^{\prime}\right)$ & Amplicon size (bp) & Primer position & Intron-spanning \\
\hline GLI1 & Reverse & AGTATGACTTCCGGCACCCT & & $7554-7573$ & \\
\hline \multirow[t]{2}{*}{ MMP2 } & Forward & TGATCTTGACCAGAATACCATCGA & 90 & $4187-4210$ & No \\
\hline & Reverse & GGCTTGCGAGGGAAGAAGTT & & $4257-4276$ & \\
\hline MMP9 & Reverse & GGCAGGGACAGTTGCTTCT & & $1044-1062$ & \\
\hline \multirow[t]{2}{*}{ GAPDH } & Forward & TCAGGCGTCTGTAGAGGCTT & 240 & $2455-2474$ & Yes \\
\hline & Reverse & ATGCACATCCTTCGATAAGACTG & & 3068-3069 & \\
\hline
\end{tabular}

RT-PCR, reverse transcription-polymerase chain reaction. 